\title{
Intrafirm Mobility and Manufacturing Modernization
}

\author{
JOHN E. ETTLIE
}

School of Business Administration, The University of Michigan, Ann Arbor, 48109-1234

(U.S.A.)

\begin{abstract}
In this article a general model of personnel flows and the innovation process is introduced. Part of this model is tested with data from domestic plant modernization projects. This model suggests that during the initiation phase of radical process innovation, the most likely type of personnel flow to be found is the interfirm movement of managers. During implementation, the model suggests that engineers move intrafirm. For the movement of manufacturing engineers the model was found to be strongly supported. More specifically, manuiacturing engineers tend to be promoted during the implementation process which becomes a major mechanism for technology transfer at the plant and division level. Firms that experiment with new organization structures and policies are more likely to experience this engineering mobility during deployment of integrated, advanced manufacturing technology. Further, this mobility is significantly associated with greater uptime and higher inventory turns for the new manufacturing system. Finally: we found the impact of mobility on performance outcomes generally unaffected by controlling for organization structure (plant size) and corporate budget for these projects. This suggests that firms do proceed from being more flexible to being less flexible as initiation turns in"o implementation of significant throughput change. Suggestions for future research are discusseci
\end{abstract}

\section{Intrafirm mobility and manufacturing modernization}

Writers in a widening circle, and with greater conviction, continue to raise the concern that we have not given sufficient attention to human resourcing planning issues for professional staff, especially scientists, engineers or technical personnel. Rather, we have become preoccupied with management succession and labor. One of the manifestations of their chronic problem, is the difficulty of promoting technical personnel into managerial positions in an organization. As Hill and Sommers (1988) put it, "When a firm promotes a good specialist, it may not only lose the service of a valued employee, but end up with an inept manager," (p. 1).

Another issue in this general area is the transfer and placement of key people associated intimately with the innovation process in an organization. There is a growing body of evidence that suggests that personnel flows and mobility is 
a rather central factor in adding to. maintaining or detracting from the innovation capability of groups and organizations (Ettlie, 1987).

As it turns out, not surprisingly, these two issues are related. That is, personnel flows, or the movement of a person or persons across an organizational boundary that has an important influence on the innovation process, often involves the promotion of that person or the assumption of more formal authority in the firm or project. It is this connection - personnel flow and promotion of technical personnel to management - that is taken up in this study.

\section{Interfirm versus intrafirm mobility}

There appears to be at least two factors, apparently independent of the innovation process, that have an influence on the rates of interfirm versus intrafirm mobility of managers and technical personnel. The first is culture, which appears to affect both people's willingness to move acro's geographic regions and organizational change philosophies. The second is industry structure. In particular, the size of firms in an industry spems to impact very heavily on interfirm mobility rates.

Cox (1988) reviews some of the literature on interfirm mobility in Japan and the United States and finds rather stark comparisons. In one study reported by Kagona et al. (1985), a comparison was made of 227 U.S. firms and 291 Jananese firms, all of them among the 1000 largest in each country. Managers and technical personnel were much less likely to move between firms in Japan than in the U.S. The survey used a seven-point scale for rating mobility. In Japan, mobility was rated 1.78 for managers and 1.97 for technical experts. In the U.S., mobility was rated 3.46 for managers and 3.45 for technical personnel. Japanese managers were significantly higher than their U.S. counterparts in their "belief that managers would not leave the company even if a higher position were available elsewhere" (Cox, 1988, p. 17).

A second study reported by the Japan Productivity Center (1984) is also reviewed by $\operatorname{Cox}$ (1988). This study involved data from 450 U.S. and 911 Japanese production, sales, and management employees. Here it was found that for Japanese respondents, $90 \%$ had been with the same firm for their entire worklife, while only $29 \%$ of U.S. respondents reported working for the same firm since they began employment. Respondents who had changed companies 3 to 5 times since they began work in the U.S. were $28 \%$ of the American sample, whereas only $1 \%$ of the Japanese respondents fell into this category. On the other hand, Cox (1988) argues that in Japan, internal movement within irms is quite high, especially as a mechanism for managerial development. Th॰re appears to be little, if any, systematic empirical data to document this well known tendency among Japanese firms, but there seems to be widespread Japanese belief in this practice.

In a recent article by Kanabayashi (1988), the beginnings of a trend away 
from lifetime employment are documented in Japan. According to one survey, "Last year about 2.7 million people, or $4.4 \%$ of the work force, jumped for greener pastures. That's up $80 \%$ from five years ago. Part of the reason for this new trend in Japan is the increasing number of foreign firms iocating there which increases the competitive pressure for new hires. Japanese corporations are beginning to foster the trend because group teamwork is fine for mass production but does not necessarily foster creativity. Sony Corporation's general manager calls this the 'stirring-up effest'."

We know precious little about the consequences of blending cultures on plant work life. There have been some mixed reports about Japanese automobile manufacturing in the U.S., where primary Japanese managers supervise American workers. One recent case is the Mazada Motor Corporation's Flat Rock, Michigan plant which builds the Ford Probe. A recent article in the Ann Arbor News suggests that the startup period for this plant has been difficult. Production began September 1, 1987, but the plant has a backlog of 2,000 cars waiting for repair before shipping. The cost of quality is reported to be quite high. Problems include "inexperienced workers, in-plant robotics and suppliers" (Ann Arbor News, 1988, p. D8). And, of course, the Probe is a new product for the Mazada-Ford joint venture.

Reports on the joint venture between GM and Toyota and the NUMMI plant in Fremont, California have also been mixed. Products shipped - even new model cars - have been of high quality and startup appears to have gone relatively smoothly with the first product (an existing Toyota design), the NOVA. However there also have been informal accourts of labor unrest. The former vice president of manufacturing at Flat Rock, Dennis Pawley, was quoted as saying that "The Japanese can't supervise Americans", and cannot understand why they have to be sold on an idea, whereas Japanese managers are "used to unquestioning obedience form workers" (Ann Arbor News, 1988, p. D8).

Pawley now works at Otis Elevator Co. and is an example of interfirm mobility from a mixed-culture setting. There is virtually no information available on the mobility of engineers of managers at either NUMMI or Flat Rock. even less information is available on the impact that mobility may have on product or process innovation.

Another good case study of mobility that is very relevant to this study is the story of Richard E. Dauch, executive vice president for manufacturing at Chrysler Corporation (Mitchell, 1986) , Dauch was an engineer who spent five years as a floor supervisor before his rise to the top at Chrysler. He believes that success with factory-of-the-future depends on training programs to prepare people for change. Observers say that it goes beyond that. Smaller size and centralized management had as much to do with it. This suggests the hypothesis that structure does impact or moderate the effect of personrel flows.

The second important factor that appears to have a very strong influence $\mathrm{cn}$. 
interfirm mobility is industry structure. For example, Jervis did a secondary analysis of the SAPPHO data and found that, "...in the instrument industry successful innovation managers may gain experience by external mobility, whereas in the chemical industry the same asset may be gained by internal mobility" (Jervis, 1975, p. 23). Jervis attributes this difference to the fact that the chemical industry has larger sized firms which results in greater opportunities for internal mobility. Generally, industries that are more concentrated have more intrafirm mobility because a larger percentage of total revenues are accounted for by a smaller number of firms. This assumes that either mobility is independent of the innovation process or technology remains constant. This does not account for the inter-industry mobility among general managers.

In a sample of 603 employees (mostly managers) of eight Canadian companies, Pinder and Schroeder (1987) found that the "objective differences between jobs and number of previous transfers do not account for much of the variability in time to proficiency over and above that accounted for by perceived job differences and perceived support in a new work setting" (p. 346). Employees with the longest self-reported times to proficiency are those that also report their new jobs were much more difficult and dissimilar from past work. Support on the job significantly reduced the time to proficiency for difficult iobs. More transfers do not necessarily prepare an employee for the next transfer, based on these results. Individual differences were not found to moderate or effect these results. For example, request for transfer, length of time sir ce last transfer, transfer versus promotion, age and education, pay raise, and tenure with company did not have any impact on proficiency above those other variables tested (e.g., difficulty). One personal variable did moderate effects. "The longer a person had been in a field or occupational group, the stronger was the correlation between perceived time to proficiency and the number of previous transfers the person had experienced" (p. 347). In other words, it took less time to become proficient after a number of transiers for the last transfer when a person had been in a field for a longer time. These results suggest that for any job and any type of transfer the time to proficiency depends mest on their perceptions of the difficulty of the move and on little else.

\section{Mobility and the innovation process}

When the effect that personnel mobility has on creativity and technological change is studied, a number of new insights develop. There appears to be evidence that the locus of innovation for radical shifts in technology is very much dependent upon personnel movement between firms, and in some cases, between industries An example is Morison's (1966) study of the Bessemer steelmaking process. Morison found that manpower flows occurred at successive stages of development and commercialization for this new process. Ettlie (1980) found this tendency among five projects in a U.S. firm representing the Indus- 
trial Gas Industry. The more significant the project was to the firm, the more likely there was change of at least one key individual associated with the project, and the greater the impact this change had on the outcome of the project. When there is much at stake firms will move special people into special positions to promote success.

There also appears to be evidence that when one examines a key initiating event in the innovation process, it tends to involve an interfirm, managerial change (Ettlie and Vellenga, 1979; Rothwell, 1978; Schendel et al., 1976). For example, Ettlie (1985) reports results on changes in packaging technology among 56 food processing firms anci interfirm personnel flows. Only $23(41 \%)$ of these firms reported any significant innovation-impact personnel additions that influenced decision-making. Of these, 15 (27\% of the total) cases involved mars agerial positions. Doz and Prahalad (1987, p. 72) report that "Based on our limited sample, the appointment of a new key executive bringing a different vision appears a necessary - but not sufficient - condition for successful strategic redirection." Further, Henderson and Clark (1989) found virtually no interfirm mobility in the photolithographic equipment industry which exhibited a consistent pattern of leader firm failure with each successive generational shift in technology. This is in general agreement with the other literature here that significant change comes to an existing firm through (although not exclusively by) the jolt of new behavior by an important officer of a firm. One way that this is likely to happen is when a new member joins the firm or business unit in an important position.

An often practiced tactic for technology transfer within firms is the movement of technical personnel or technical managers with a project as it progresses through the various stages of development. What is more, actual jobs taken on by manufacturing engineers often become the defacto manufacturing strategy of a firm (Wood and Coughlan, 1988). This, coupled with the other

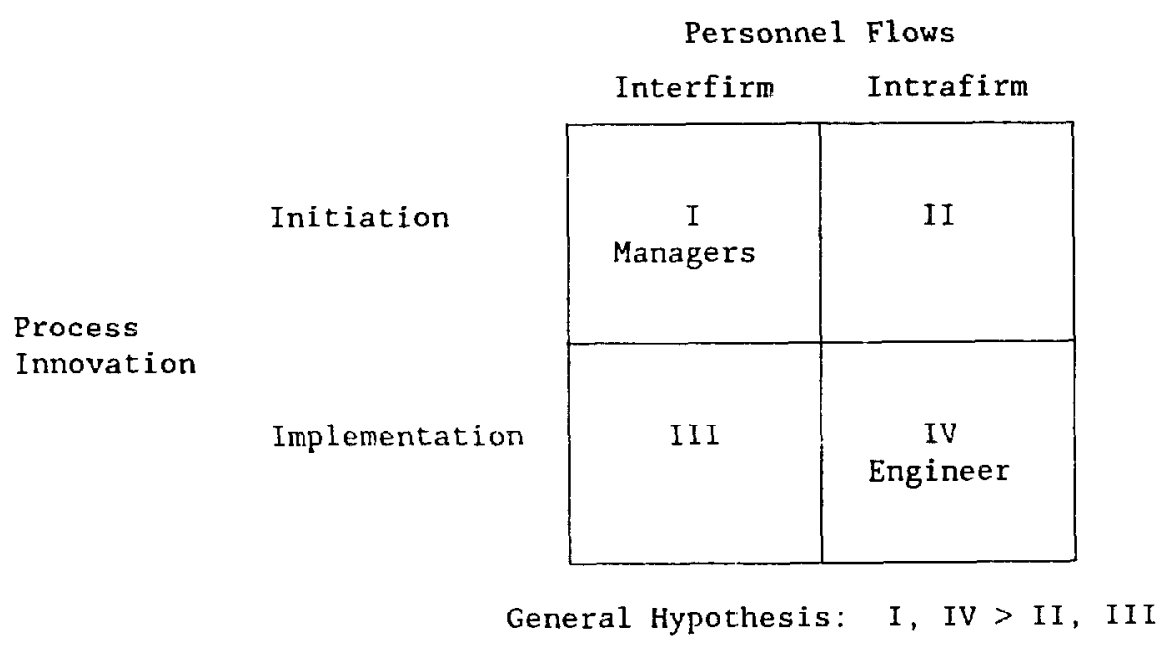

Fig. 1. Interfirm versus intrafirm personnel fiow and the innovation process. 
findings suggests a general model of interfirm versus intrafirm personnel flow and the innovation process. This model is summarized in Fig. 1.

In this model, it is suggested that the most likely personnel flow for initiation of process innovation shift (through-put technology changes) is going to be the result of interfirm (or interbusiness unit) mobility - most likely involving a senior manager. On the other hand, during implementation of process innovation, movement of engineers is the most likely change necessary to ensure smooth transition from startup to steady-state production.

\section{Propositions}

The first part of the general model (Fig. 1) has been supported by findirgs cited earlier, like those in Schendel et al. (1976). On the other hand, the second part of this model, at least for manufacturing or operations (service) process technology implementation, has not been empirically tested.

Type of mobility

As indicated in Fig. 1, engineers - especially manufacturing engineers - are likely to dominate mobility activity during implementation of new process technology. Therefore, the following proposition is offered for testing.

Proposition. Intrafirm personnel flows during the implementation of process innovation are likely to involve the promotion or mobility of engineers.

One of the reasons that this proposition is offered is a condition suggested by the general model in Fig. 1. During the implementation process, a greater degree of stability is assumed to be required when compared to the initiation phase of adoption of new through-put technology. Therefore, manager are less likely to move during innovation implementation. If movement does occur, the model predicts, it is less likeiy to have any substantial influence on the outcomes or progression of the new technology to sieady-state. The model also predicts that engineering personnel are unilikely to move at the initiation stage of process innovation.

\section{Administrative innovation and mobility}

One of the implicit assumptiviss of the personnel flow and mubility research stream associated with technological innovation is that these boundary crossings are not the exclusive choices of individuals. Other factors such as policy and organization structure influence mobility. For example, Ettlie (1985) found that structural autonomy and new, higily visible positions in food companies can go far to accommodate the managers who are newcomers to the firm and 
capture the innovative benefits of their arrival. In this case, it was arinvtion of new packaging technolugies. In addition, it was found that comple $\_$, decentralized organizations enhance the impact of interfirm personnel flows - most of which involved mubility of managers.

In the case of intrafirm mobility and modernization, which is the focus of this research, it was suspected that there is a connection between the simultaneous use of administrative innovations and flexible automation to modernize plants. An earlier report stated that about half of all domestic plants are using some type of novel administrative practice to increase the probability of a successful factory innovation (Ettlie, 1988). Since human resources are so rare but critical to the success of modernization programs, it was thought that a likely relationship existed between the implementation strategy used by a firm and the mobility of engineers.

The general model summarized in Fig. 1 suggests that engineers will probably move along with the technology as it transists stages in the startup process. Consequently, engineers are most likely to be promoted to factory management in innovative plants. The most logical promotion consistent with the general model is for these engineers to supervise the areas that is being enhanced with new technology. Alternatively, engineers - especially manufacturing engineers - might be promoted to staff management positions, like manufacturing engineering management, because in most domestic plants this engineering management position reports to manufacturing, not engineering. The following propositions are offered for testing.

Proposition 2. The typical personnel flow during modernization involves manufacturing engineers who are likely to be promoted to manufacturing management supervising the area where the system was installed.

Proposition 3. Intrafirm personnel flows during modernization tend to occur in plants where administrative innovations are being used for deployment.

\section{Type of administrative experiment and mobility}

Susman (1987) finds in a review of the literature that engineers can only aid in use of advanced manufacturing technology if organizational structures change along with technology. There is no indication that use of new technology reduces the need for engineers, but that engineers can become more efficient with the appropriate use of new systems. Technicians, on the other hand, may be less required after these new advanced manufacturing technologies are successfully adopted.

Assuming that there is a relationship between a firm's ability and willingness to use administrative experiments for modernization and engineering mobility, it might be interesting to explore what kind of administrative innovation 
was used and if it had any direct relationship with the mobility. This is an exploratory question that will be investigated with the data available.

\section{Mobility and corporate investment in modernization}

There are any numıber of writers and practitioners that have expressed concern over internal or corporate technology transfer issues in modernization of plants and introduction of new products (e.g., Rubenstein, 1989). In one way, this surfaces as the issue of increasing the return on investment of R\&D applied to the manufacturing engineering function. That is, if know-how acquired during modernization can be diffused across engine plants and manufacturing operations, and then across units or divisions within a firm, there is a much better use of human resources and greater cohesiveness of operations from a corporate view.

In order to investigate this issue, the relationship between mobility data and information on the corporate role in modernization was also explored. No propositions were offered in this area, although Ettlie (1985) did find that the impact of interfirm mobility was moderated by organizational structure and perceived availability of slack resources, which is discussed below.

\section{Intrafirm mobility and modernization outcomes}

As Hill and Sommers (1988) point out, promotion for scientists and engineers into managerial positions is one of the few rewards available to make sure that successful technologists are recognized. We assume this applies to the process innovation process as well as R\&D settings, so it is also likely that this mechanism operates as an incentive in manufacturing settings. About onethird of all engineers eventually become managers (Badawy, 1988, p. 31). It is predicted that in cases where engineering mobility is tied to the modernization effort, it will result in better performance among subordinate engineers and higher team performance which will result in greater success on the modernization project. The fourth proposition is as follows:

Proposition 4. In firms where engineering mobility occurs during the modernization process, and where the engineer responsible still remains involved in either project or manufacturing supervision with the new system, the modernization program is more likely to be successful.

Another way of looking at this issue, using a technology transfer perspective, is that engineering mobility is a key mechanism for process technology transfer.

In earlier work (Susman, 1987; Ettlie, 1985) it was suggested and found that organizational structure moderates the impact of mobility and occupational impart on innovation outcomes like adoption. However, we assume that a gen- 
eral principle of change is operating in these settings whereby a firm or business unit becomes less flexible over time and more set in its way as it moves from the initiation phase of transition to the implementation stage of change. This suggests that the moderating effects of resources and organization structure will have less impact - if any - during the implementation phase of modernization. This thought is summarized in the following proposition:

Proposition 5. Resource availability and organization structure will not moderate the impact of engineering mobility on performance outcomes during the implementation phase of modernization.

This idea is a powerful one if supported empirically because it has implications for continuous improvement, managing the innovation process of throughput and the management of engineers who may become bored with noncreative tasks of implementation.

\section{Methndology}

The design for this study called for a three-panel, longitudinal data collection, with each visit to modernizing plants separated by one year. We sampled firms in 1984, and collected data primarily in 1985, 1986, and 1987. All firms, plants, and individuals were guaranteed anonymity. However, only third panel data are used here because twelve cases had to be replaced during the course of the study. A challenge to the patent covering nuch of this technology caused this attrition.

\section{Sample}

The sample was compiled by merging lists of announcements of significant, multiple component, flexible manufacturing and assembly systems from several sources. Trade publications like Automation News, Metalworking News, all the major robotics publications, and American Machinist were screened for announcements of system purchases. We started with early 1983 trade publications and information provided by vendors and other firm informants. Since we expected at least a $50 \%$ response rate, we worked until we had a list of about 80 cases, which took use well into 1984 .

In order to be eligible for the study, firm was required to have committed resources for the purchase of a system. A total of $39(66 \%)$ of the first 59 eligible plants we contacted agreed to participate in the study for the first panel data collection. There were actually 40 plants visited in the first panel, but one firm ultimately refused to release the data for analysis.

Responding and nonresponding firms were compared on number of employees and no significant difference was found $(t=1.7$, n.s. $)$. Responding and non- 
responding firms were also compared by distribution of cases by SIC code category. Most firms feli within the major manufacturing groups 34-37. For responding firms, $13.9 \%$ fell in SIC 34 (fabricated metal products like hand tools), while nonresponding firms had $10.5 \%$ in this category, and for SIC 35 (machinery, except electrical), $38.9 \%$ of responding firms were listed as having this as their primary code while nonrespondents had this SIC code first in $36.8 \%$ of the cases. Several sources of data were used for these comparisons including Dunn \& Bradistreet and Standard \& Poor's.

There were four firms with two or more plants in the sample, all located in different divisions. One-way analysis of variance was used to check for independence of plant cases for each major scaled variable, and none of the comparisons were significant. We concluded that the sample we drew was reasonably representative of a population of domestic modernizing plants. We also found no significant differences across SIC categories for the purchase cost of system. Major variable correlations of union vs. nonunion, and government contract vs. nongovernment were nonsignificant. The one exception was that larger firms were more likely to be unionized.

All regions of the country were represented and the majority ( 26 or $67 \%$ ) of the systems purchased were flexible manufacturing systems, defined in very broad terms to include multiple machine, computer-integrated, materials-handling intensive, discrete parts producing systems. There were also five flexible assembly systems, and three robotic cells. In the third panel of data after replacement for attrition, 19 (48.7\%) were categorized as flexible manufacturing systems because more robotic and flexible assembly systems were now included.

The first panel system average cost was $\$ 3.6$ million but $10(28 \%)$ of the plants spent less than $\$ 1$ million initially. Three of our original 39 plants closed in the oil well supply industry due to economic conditions. Two of these three plants closed before the second panel of data was collected. One plant was declared a mature implementation case, with no significant change in production performance, so they did not participate through the third panel. As it turned out, one of these cases was in fact a plant where a robot was no longer being used - a failure to implement case. Two plants wanted to delay data collection until the third year of the study. So by the end of the second panel of data collection, 34 participating plants remained. No additional cases were added during the second panel.

Seven cases refused to participate through the third panel, one because the plant had closed and the balance because they no longer valued participation or their data were becoming sufficiently detailed to be classified as proprietary, even with guarantees of confidentiality. Most of the other refusals came from the legal department due to a patent challenge to the FMS concept. We replaced these 12 cases with comparable plants, but with systems that were up and running so that performance data would be available, in regions where the nonparticipating or ineligible plants had been located - primarily in the south 
and midwest. A total of 51 plants participated in at least one panel of data collection in this project. Each of these plants wore visited, and an average of two to three interviews were conducted at each site.

There was no apparent relationship, based on all data we could collect frem vendors, and in the open trade press, between performance of these systems and attrition or participation in the project. This excludes the one exception of a robotic cell mentioned earlier. We had a total of 7 of $34(21 \%)$ complete data cases in the final panel reporting $60 \%$ or less utilization (the average was $72.3 \%$ ), so we did not eliminate failures or marginal successes from the data. However, for the purposes of this report, concentration on just third panel data seems prudent in order to maximize the number of complete data observations without estimating cases for missing data, which averaged the typical $2-5 \%$ for each item on the interview schedule.

Participating plants were operated primarily by large firms, with the vast majority (34) in the first panel having more than 500 employees. Plant sizes also tended to be large, with just over $55 \%$ having more than 500 employees on site. The same distribution held for third panel data after replacement. Of the 39 plants visited in 1987, $16(41 \%)$ had fewer than 500 year-round, full-time employees. The smailest plant had 12 people, the largest had 12,000, an the median plant had 850 employees.

Over 100 personnel were interviewed in the first panel data collection starting late in the fall of 1984 and winter of 1985 . One primary respondent was identified in each case, although we usually interviewed 2 or 3 people at each plant. These primary respondents were most often middle managers (53\%). This pattern was virtually identical in the second data collection, one year later, because no new cases were added. In the third panel, more top managers were the primary respondent (20) and fewer middle managers (10) but combined they accounted for $30(76.9 \%)$ of the primary information person.

It is important to repeat that the sample does not represent all durable goods manufacturing plants but a more select group of firms modernizing their facilities with advanced manufacturing systems that were computer controlled and software as well as hardware intensive. Since the study began, almost every major firm in each of these durable goods industries has now revealed that they too have modernization programs. Therefore, as time goes on, this sample actually becomes more representative of all domestic manufacturing in these major industry groupings.

\section{Personnel flows}

We asked each key interview respondent the following question:

"Has there been any significant movement of personnel associated with this project since it began? (Probe: Turnover, promotion, vendor personnel changes, 
added new team members.)" The Yes answer was coded 1, No answers were coded 0 .

When we coded the responses, we excluded turnover and allocated those responses to another question on personnel turnover. There were 36 valid answers, $22(56.4 \%)$ of the 39 cases were yes. As will be seen later, the vast majority of the data related to movement of manufacturing engineers (see Table 1). As a result we created a new variable called "extent of manufacturing engineering mobility", which was coded as follows: (1) no mobility of manufacturing engineers was coded $0 ;(2)$ at least one manufacturing engineer promoted to staff management, like manager of manufacturing or industrial engineering, was coded $1 ;(3)$ at least one manufacturing engineer promoted to line manufacturing management was coded 2; and (4) if at least one manufacturing engineer was promoted to staff and line each, the case was coded 3.

\section{Administrative innovation}

The adoption of novel administrative programs was evaluated for these analysis based on the content analysis of responses to the question: "What administrative innovations or programs (if any) were put in place specifically to accommodate the introduction of the new technology system?" In the first panel data $22(56 \%)$ of the plants were found to have put into place at least one new policy, structure or practice specifically to facilitate implementation of the system. After replacement in the third panel of a total of 12 new cases, this percentage was $53.8 \%$ with 21 of the final 39 plants reporting some type of administrative innovation for deployment. Nineteen appear in Table 1, due to missing data on personnel flows. The most frequent change was use of engineer-blue collar teams.

Tied for the second most frequent type of administrative innovation was the use of a new structure for implementation with four plants. Here we have cases of decentralization of corporate manufacturing engineering to plants, the installation of area (dedicated) maintenance from plant-wide service, a common computer-integrated manufacturing management position created whereby design and manufacturing engineering report to a common person, the use of a maintenance supervisor and skilled trades as operators vs. typical area supervision of an automated system, and the consistent and sustained use of management by objectives.

Also ranked second was "Business unit technology strategy", which needs some explanation and rircicsion of examples. Business strategy is normally thought of as the way in which a company has decided to compete (e.g., price, product innovation, etc.) in a given market. There were four of these administrative experiments (Table 1). The most pronounced case involves the use of a flexible factory to implement a new company strategy to manage components suppliers, as well as customers. Another firm can switch between two 
metal suppliers - aluminum or copper. Here the emphasis is on gaining control of supplied-part price and quality and being able to move from one part family and group of parts or materials to another across suppliers freely. It also involved the contracting out of purchasing for nonproduction stores - a radical shift for this company. Other examples include introduction of a "greenhouse" within a plant - an area set aside for production technology experimentation - and more importantly, the integration of this greenhouse into daily operations. All these cases have some specific, clear strategy being implemented by the new technology program - not a trial and error process of equipment replacement.

These themes represent the essence of these cases but they do not include all the innovations used in each plant. There were two examples of personnel scheduling experiments in the study, one in the first panel and one in the third panel. These new work schedules involve process industry type work weeks, 4 days and 12 hours, alternating with 3 days. Teams often have a problenı coordinating between their efforts in these circumstances, so it will be interesting to see the outcomes of these administrative innovations. There are also training and compensation experiments, some funded by state and local agencies supporting these plants.

\section{Corporate influence on modernization}

We asked three questions concerning corporate influence on the modernization process to see if it had any relationship to mobility among engineers in plants or divisions: (1) "There is a line in the budget for manufacturing engineering has helped to coordinate design and manufacturing on this project", and (3) "Our R\&D unit was involved in the designing of this system". The answers to these three questions were coded as follows: "yes" was coded 3, "in process" was coded 2, and "no" was coded 1.

\section{Dependent variables}

A total of rine performance measures designed to capture a full range of effectiveness dimensions were included as part of the interview process and produced sufficient data to be analyzed here. The original plan was to compile at least one index of modernization effectiveness using many individual, objective measures. We decided not to take this approach. First, there are good theoretical reasons to keep the performance measures segregated, since different strategies affect outcomes differentially (Hambrick, 1983; Cameron, 1986). Secondly, these performance measures differ in their basis of inference, i.e., some are self-reported, some are obtained from organizational records, and mixing them on a scale eliminates the possibility of determining construct validity and confounds sources of method variance (Campbell and Fiske, 1959). 
Third, and finally, if these performance measures are not inter-correlated, they cannot be forced onto scales to represent dimensions. Most of these measures did not have statistically significant relationships. Descriptive statistics for these measures appear in Table 2 later.

The first dependent variable was a global measure of modernization performance and was the amount of unanticipated funds used on the project as a percentage of the original system purchase price. In the third panel of data, this averaged about $8 \%$, and $10 \%$ is often the number given as buffer budget on risky manufacturing upgrade projects. The second global measure of performance was the amount of time needed to install the system and get it running. For the third panel of data, this averaged about 11.7 months. A third, plant level measure, reduction in floor space requirements, was dropped because no one reported it as a priority outcome for modernization.

Seven system level variables were measured. First, the percentage of target cycle time achieved was recorded and averaged $94 \%$. It is equivalent to the ratio of actual cycle time in net parts per hour on average, divided by target cycle time in net parts per hour. Second, we asked respondents to show us production records indicating the amount of uptime (time available for production, average $=87.3 \%$ ) and utilization time (time actually producing parts, under cycle control, average $=72.3 \%$ ), based on a two-shift basis. Third, we obtained data on scrap and rework percentages (of total manufacturing cost) for the system (average $=2.91 \%$ ) and the plant (average $=4.26 \%$ ), throughput time reduction as a percentage based on comparisons of before and after the system was installed (average $=54 \%$ ), and change over time in hours (average $=6.25$ hours). Finally, inventory turns $(\bar{x}=38.3)$ for the system were included, although only 14 complete data cases were available.

Unfortunately, personnel turnover, absenteeism, grievances, and several other measures of human resource management had very few cases reporting or content was sketchy, e.g., grievance type. Return on investment numbers were included in one method of analysis below, although less data are available on this accounting measure.

Validation of three of these scales, cycle time, uptime, and utilization, was accompl shed by correlating case scores, where available, with evaluations from an industry expert and consultant on FMS. In a blirid test, this independent judge assigned scores of 1 (failure), 2 (poor), 3 (average), 4 (good), and 5 (excellent) to his nine cases that we had avaijable production data on from plant visits. The resulting Kendall correlations were $\tau=0.53(p<0.06)$ for cycle time; $\tau=0.56(p<0.05)$ for uptime; and $\tau=0.45(p<0.08)$ for utilization. This is a good indication of adequate construct validity for these types of variables using two bases oî inference (Campbell and Fiske, 1959). 


\section{Results}

\section{Mobility and new process implementation}

Although one cannot test the general model summarized in Fig. 1 unless both adoption and implementation of process technology have been compared with non-innovating plants, propositions derived from the model, that were presented earlier, can be evaluated. This was done with the complete data cases available from the third panel of information in the domestic plant study.

Proposition 1 states that interfirm personnel flows during implementation of process innovation are most likely to be promotion (mobility) of engineers. In Table 1, a summary of the types of personnel flows reported by respondents in the 39 domestic plants included in the last sample is presented. Recall that in each and every case, the changes involved people with roles central to the team. A total of $22(56 \%)$ of these 39 cases experienced at least one personnel flow during implementation - slightly higher than the $41 \%$ rate of interfirm mobility reported earlier (Ettlie, 1985). In 11 of the 22 plants where there was at least one documented case of a personnel flow, a manufacturing engineer was promoted to manager. These 11 plants had promotions involving $14 \mathrm{en}$ gineers (one plant had three cases, another had two), and the others hsd one each. Among these 14 engineers, nine were promoted into manufacturing inanagement and assumed nositions such as "FMS manager" and areas sunervision, and in ont case, piant manager. The first category also included two cases of promotions to project manager. In five of these 14 instances, engineers were promoted to engineering supervisor. Most typical was manager of manufacturing engineering.

A distant second in Table 1 is promotion of non-engineers, e.g., hourly, which

\section{TABLE 1}

Intrafirm personnel flow during modernization

\begin{tabular}{lll}
\hline \multicolumn{2}{l}{ Type of personnel flow } & $\begin{array}{l}\text { Plants } \\
f(\%)\end{array}$ \\
\hline 1. & At least one manufacturing engineer promoted to & $11(50 \%)$ \\
& manager & \\
2. & Non-engineer promoted (e.g., hourly, supervisor, etc.) & $5(23 \%)$ \\
3. At least one manufacturing engineering rotation & $4(18 \%)$ \\
4. $\quad$ Other & $\frac{2(9 \%)}{22(100 \%) \text { plants of } 39 \text { surveyed }}$ \\
\hline
\end{tabular}

aThere were two cases with multiple manufacturing engineer promotion. Of the 14 total individuals involved, nine were promoted to manufacturing management as system supervisor or above or to project manager; five were promoted to manufacturing engineering supervisor. 
occurred in five plants. Almost as frequent was engineering rotation which occurred in four plants.

Not only do these results support Proposition 1, they sustain Proposition 2 as well, which states that the typical personnel flow durin $r$ implementation of process innovation will involve engineers following systems ("flowing") into the plant by taking supervision over their production.

There are some interesting descriptive comparisons that can be made from these results and earlier findings. Ettlie (1985) found that there were $23(41 \%)$ cases of personnel flows that helped initiate shifis to radical packaging technology in the food industry, and $15(27 \%)$ of cases involved managers. In the present study of 39 plants, $22(56 \%)$ experience some sort of personnel transfer after adoption, and $11(28 \%)$ of these cases involved engineers. That is, in both cases, about $27 \%$ or $28 \%$ of the cases fell in the predicted cells of the model (Fig. 1). Perhaps this is a coircidence, but the parallel seems important to note at this stage of this research. These percentages do include cases where there was no significant personnel flow during part of the process that was studied.

One case, not included in Table 1 kecause the data was not detailed enough to specify the type of personnel flow, illustrates the magnitude of personnel changes during a large modernizatiois program. In this particular case, the project was a 10-year, computer-integrated manufacturing (CIM) program in planning and implementation where, over a seven-year period, seven of ten key managers on the program had moved up in the company. There was almost a total absence of any interfirm personnel flow renorted in the third panel of data collection on this project. In one, rare instance, which involved the case of a vice preident returning to he firm after leaving earlier, it was difficult to evaluate the impact this "mobility" had "n the modernization project. Turnover among 'sperators, etc. was not counted in this data because of the stariup period and $\epsilon$ ase of replacement. Personnel turnover data for plants and even areas of a plart was not reported in the majority of these cases.

Other data that was not included here (Table 1), are cases where people are trained on ore shift, usually first shift, and then moved to second or third shift. Physical movement between buildings of personnel was also excluded.

\section{Administrative innovation and mobility}

In order to test Proposition 3, which states that plaats that adnpt administrative experiments for modernization are also more likely to have persnnnel flows that are interfirm transfers, a cross-tabulation of data for these two concepts was accomplished. The results appear in Table 2.

Not only is there a significant correlation between intrafirm personnel flow and use of admiristrative experiments during modernization, with $r=0.32$ ( $p=0.03$; Kendall's $\tau$ and Pearson's $r$ are the same for a $2 \times 2$ table, although significance levels vary slightly) a large percentage of the data are on the di- 
TABLE 2

Cross-tabulation of intrafirm personnel flow and administrative innovation during modernization

\begin{tabular}{llll}
\hline $\begin{array}{l}\text { Intrafirm } \\
\text { personnel flow }\end{array}$ & \multicolumn{2}{l}{$\begin{array}{l}\text { Administrative } \\
\text { innovation }\end{array}$} & \multicolumn{2}{l}{ Total } \\
\cline { 2 - 4 } & No & Yes & \\
\hline No & 9 & 5 & $14(38.9 \%)$ \\
Yes & 7 & 15 & $22(61.1 \%)$ \\
Total & 16 & 20 & 36 \\
& $(44.4 \%)$ & $(55.5 \%)$ & $(100 \%)$ \\
\hline
\end{tabular}

$r=0.32(p=0.03)$.

TABLE 3

Cross-tabulation of engineering-mobility and administrative experiment type

\begin{tabular}{|c|c|c|c|c|c|}
\hline \multirow{2}{*}{$\begin{array}{l}\text { Type of } \\
\text { administrative } \\
\text { experiment }\end{array}$} & \multicolumn{4}{|c|}{ Engineering mobility } & \multirow[t]{2}{*}{ Totals } \\
\hline & None & $\begin{array}{l}\text { Mfg. engr: } \\
\text { promoted } \\
\text { to staff }\end{array}$ & $\begin{array}{l}\text { Mfg. } \in \text { rigr. } \\
\text { promoted } \\
\text { to line }\end{array}$ & $\begin{array}{l}\text { Mfg. engr. } \\
\text { promoted } \\
\text { to both }\end{array}$ & \\
\hline $\begin{array}{l}\text { Sociotechnical } \\
\text { teams }\end{array}$ & & & 1 & & 1 \\
\hline New job concepts & 1 & & & & 1 \\
\hline $\begin{array}{l}\text { Technology } \\
\text { agreements }\end{array}$ & & 1. & & 1 & 2 \\
\hline New strategy & 2 & 1 & 2 & & 5 \\
\hline New structures & 3 & & & 1 & 4 \\
\hline $\begin{array}{l}\text { Engineering-blue } \\
\text { collar teanis }\end{array}$ & 4 & & 2 & & 6 \\
\hline Totals & 10 & 2 & 5 & 2 & 19 \\
\hline
\end{tabular}

$\overline{\chi^{2}}=16.9(\mathrm{df}=15, p=0.32)$

agonal of this table. That is, nine of the 36 complete data cases representing modernizing plant report neither a significant personnel flow nor an administrative experiment, and 15 plants report both. Most rare, rith five cases, is 


\section{TABLE 4}

Correlations between corporate involvement in modernization and manufacturing engineer mobility

Extent of manufacturing

engineer mobility

\begin{tabular}{lcc}
\hline $\begin{array}{l}\text { Line item in budget for } \\
\text { manufacturing R\&D }\end{array}$ & $0.44^{*}$ & $(n=33, p=0.005)$ \\
$\begin{array}{l}\text { R\&D helped design new system } \\
\begin{array}{l}\text { Corporate manufacturing engineering } \\
\text { helped coordinate }\end{array}\end{array}$ & -0.00 & $(n=83, p=0.49)$ \\
\hline
\end{tabular}

${ }^{*} p<0.01$.

the situation where an administrative experiment is reported, but no significant personnel flow occurred. There were seven reported cases to complement this latter type - where there was a significant personnel flow but not administrative experiment. Given that all but two of the yersonnel flows in the sample were unqualified intrafirm transfers, Proposicion 3 is supported by these results. This strongly suggests that administratively innovative firms orchestrate the movement and mobility of people when they modernize.

The exploration of the reiationship between the specific type of administrative experiment and type of engineering mobility is possible by examination of Table 3. This cross-tabulacion shows the range of administrative experiment type starting with the ise sirently reported, sociotechnical teams, to the most frequenily reported types, new standings in the business unit and engineering-blue coliar teams. Wese tyes are arrayed against the four types of -xtent of mokility among engines: ruring modernization: (1) none; (2) at least one promotion to staff manager: (3) at least one promotion to manufacturing management; and (4) at least one promotion to staff and one promotion to line management during modernization.

The Chi-square statistic for this table (one nominal, one ordinal scale) is $16.9(\mathrm{df}=15, p=0.32)$ which is nonsignificant. There does not appear to be any emergent pattern in the relationship between the actual type of administrative innovation selected as measured here and mobility for this sample.

\section{Mobility and corpcrate involvement in modernization}

The correlations between the three questions asked pertaining to corporate role in modernization and extent or the type of engineering mobility are presented in Table 4.

When there was a line item in the budget for manufacturing $R \& D$, it was significantly correlated with ranufacturing engineer mobility, with $r=0.44$ $(n,=33, p=0.005)$. There was no relationship between extent of manufactur- 
ing engineering mobility and the involvement of R\&D in designing the new system, nor when corporate manufacturing engineering helped to coordinate design and manufacturing during modernization. Apparently, resources are what counts here.

\section{Intrafirm mobility and modernization outcomes}

The correlations between type of manufacturing mobility and performance outcomes of the modernization project are presented in Table 5. Two of these coefficients were statistically significant. First, the greater the mobility, the higher the uptime on the nev system, with $r=0.32(n=33, p=0.038)$. Second, greater mobility and inventory turns for the new system were significantly correlated, with $r=0.48(n=14, p=0.042)$. Two other coefficients approach statistical significance in the predicted direction. They were for mobility and overbudget percentage, with $r=0.32(n=27, p=0.054)$, and for throughput time reduction, with $r=0.34(n=22, p=0.062)$. The controlling for resources (budget) and structure (using plant size as a proxy) does not appear to influence the significant correlations between extent of mobility and performance outcomes.

Referring again to Table 5 to results for testing of Proposition 5, one finds that the impact of these mohility scores is moderated in only one of the eight

\section{TABLE 5}

Correlation between manufacturing engineer mobility and modernization outcomes

\begin{tabular}{lcccc}
\hline & \multicolumn{2}{l}{$\begin{array}{l}\text { Extent of manufacturing } \\
\text { engineer mobility }\end{array}$} & \multicolumn{2}{l}{ Controlling for } \\
\cline { 3 - 5 } & & & Budget & Plant size $^{\mathrm{B}}$ \\
\hline \% over budget & $-0.32^{* * *}$ & $(n=27, p=0.54)$ & $-0.41^{* *}$ & $-0.31^{* * *}$ \\
\% of target cycle time achieved & 0.14 & $(n=30, p=0.24)$ & & \\
Uptime & $0.32^{* *}$ & $(n=33, p=0.038)$ & $0.27^{* * *}$ & $0.33^{* *}$ \\
Utilization & 0.19 & $(n=32, p=0.15)$ & & \\
Scrap and rework & -0.15 & $(n=25, p=0.24)$ & & \\
Throughput time reduction & $0.34^{* * *}$ & $(n=22, p=0.06)$ & 0.09 & $0.32^{* * *}$ \\
Time to install & -0.16 & $(n=26, p=0.22)$ & & \\
Change-over time & 0.30 & $(n=18, p=0.12)$ & & \\
Inventory turns in system & $0.48^{* *}$ & $(n=14, p=0.04)$ & $0.47^{* *}$ & $0.45^{* * *}$ \\
\hline
\end{tabular}

"Number of employees.

${ }^{* *} p<0.05 .{ }^{* * *} p<0.10$. 
significant correlations. The other seven remain statistically significant with unchanged signs. This suggests that as the innovation process proceeds from initiation through implementation, structure and resources are less likely to moderate the innovation process as expected. Firms appear to become less flexible as this process unfolds. It also raises the age-old issue of how one simultaneously marages creativity and change with stability and effectiveness.

\section{Summary and conclusions}

People cross organizational boundaries during their careers and in some cases this has very important implications for the firm and the individual. In this study we have focused on the impact that crossing boundaries within a firm has on the outcomes of the innovation process. When a company modernizes facilities with significant new processing technology, the most typical type of personnel flow associated with change-over is the mobility of manufacturing engineers. These engineers are promoted into staff-engineering, manufacturing and project management positions and there is strong relationship between this mobility and the plant's willingness to experiment with other organizational experiments or new policies. The extent (what type of promotion) of manufacturing engineering mobility is directly related to the willingness of the firm to budget resources for manufacturing $R \& D$, but not to other corporate initiatives in our sample of firms and plants. finally, the greater the extent of this mobility, the more likely the firm will also report much greater upiime and high inventory turns for the new technology manufacturing system.

These results, taken together with other empirical findings on personne! flows and the innovation process, support a general model presented in this paper. Apparently, there is an increasing amount of evidence to suggest that there is a relationship between the stage of the innovation process (initiation versus implementation) and the type of personnel flow that is typical during this stage. In particular, it appears that managers move between firms during initiation of the innovation process and engineers - particularly manufacturing engineers - move into management positicns within their firm during implementation of innovation. This pattern is probably part of an organized strategy in most companies we have studied, although there is still much room for the old saying that "beirg at the right place at the right time", counts for much because of the rarity of talented, experienced people that can have a significant influence on the innovative capacity of an organization.

An interesting twist of the established pattern predicted by the model came to our attention recently on another project where we studied major process change in an electronics manufacturer. The general model was supported - a top manager came first, initiated change, then engineers moved later after the automation equipment was selected - but these "best" engineers were gradually moved to other hot projects out of the division and the engineers that had 
originally stayed behind were then called on to implement the results of the first wave of engineers plans. There were, in essence, two significant mobility waves in this case which are not explicitly predicted by the model. The model needs refinement to be more useful.

There are continuing methodological problems in this line of research and in this study that need improving, as well. We have still to accomplish a long term longitudinal study on the process. What is more, we have not controlled for noninnovating cases, or sorted out the relative impact of personnel flows in this process. We are beginning to know something about as radical process change happens, but incremental change involves transfers as well. The model does not account for this comprehensive phenomenon.

What remains to be investigated here are the details of the human resource policy that is coordinated with manufacturing and modernization strategies to accomplish these mobility efforts. Much of what passes for strategy in the human resource area is still justification of top management decisions rather than strategic planning, even in the cases we have studied. How do these experiences translate into policy? How does the corporation capitalize on learning from the modernization experience and maximize return on this type of investment? How do the individuals fare in this process?

\section{Acknowledgements}

Work in this areas was supported in part by the National Science Foundation under Grant Number ISI 82-18494 and ISI 85-00496. The opinions herein are those of the author and do not necessarily reflect the official position of the National Science Foundation. Additional funding for this project came from DePaul University, the Industrial Technology Institute and The University of Michigan. The author would like to thank the firms and individual participants in this research for their patience and cooperation. Research assistants on this project were Ernie Reza, Bobbie Turniansky, Mark Vanzant, Calvin Chang, Stacy Reifels, Tom Short and Christopher Getner.

\section{References}

Ann Arbor News, 1988. Hitches, cultural differences trouble Mazda's Flat Rock plant. August 28: D8.

Badaway, Michael K., 1988. Managing human resources. Res. Technol. Manage., 31 (5) (September-October): 19-35.

Cameron, K.S., 1986. Effectiveness as paradox: conflict and consensus in conception of organizational effectiveness. Manage. Sci., 32 (4): 539-553.

Campbell, D.T and Fiske, D.W., 1959. Convergent and discriminate validation by the multitraitmultimethod matrix. Psychol. Buli., 56: 81-105.

Cox, Taylor, $\mathrm{Jr}$., 1988. A cross cultural analysis of factors impacting strategy implementation: the U.S. vs. Jepan. Working paper, The Fuque School of Business, Duke Univesily, Durham, Ni. 
Doz, Yves and Prahalad, C.K., 1987. A process model of strategic redicrection in large complex firms: the case of multinational corporations. In: Andrew M. Pettigrew (Ed.), The Management of Strategic Change. Basil Blackwell, Oxford, UK, pp. 63-83.

Ettlie, J.E., 1980. Manpower flows and the innovation process. Manage. Sci., 26(11) (Novt nber: $1086-1095$.

Ettlie, J.E., 1985. The impact of interorganizational manpower fluws on the innovation process. Manage. Sci., 31(9) (September): 1055-1071.

Ettlie, J.E., 1987. Personnel flows and modernization in manufacturing. Panel on Scientific Mobility and Technological Innovation, SSSS Conference, Worchester, MA, November 19-21.

Ettlie, J.E., 1988. Taking Charge of Manufacturing. Jossey-Bass, San Francisco, CA.

Ettlie, J.E. and Vellenga, D.B., 1979. The adoption time period for some transportation innovations. Manage. Sci., $25(5)$ : 429-443.

Hambrick D.C., 1983. Some tests of the effectiveness and functional attributes of Miles and Snow's strategic types. Acad. Manage. J., 26(1): 5-26.

Henderson, R.M and Clark, Kim B., 1989. Generational innovation: the reconfiguration of existing systems and failure of established firms. Working paper 3027-89-BPS, Sloan School of Management, MIT, Cambridge, MA.

Hill, Raymond E. and Sommers. Trudy L., 1988. The Transformation from Technical Professional to Technical Manager. Industrial Development Division and School of Business Administration, The University of Michigan, Ann Arbor, MI.

Hitches, Cultural differences trouble Mazda's Flat Rock plant. Ann Arbor News, (August 28, 1988): D8.

Hervis, P., 1975. Innovation and characteristics of individuals. IEEE Trans. Eng. Manage., EM22(1): 19-27.

Kagona, T., Nonaka, K.S. and Okumura, A., 1985. Strategic vs. evolutionary management; U.S.Japan Comparison of Strategy and Organization. Elsevier, Amsterdam, The Netherlands.

Kanabayashi, Masayoshi, 1988. In Japan, Employees are switching firms for better work, pay, Wall Street J., LXIX (253): A1, A14.

Japan Productivity Center, 1984. Managerial behavior in Japan and the U.S.A.

Mitchell, Russe.', 1986. High tech to the rescue. Bus. Week, (June 16): 100-104.

Morison, Elting E., 1966. New Machines and Modern Times. MIT Press, Cambritge, MA.

Pinder, Craig C. and Schroeder, Klaus G., 1987. Time to proficiency following job transfers. Acad. Manage. J., 30 (2): 336-353.

Rothwell, R., 1978. Some problems of technology transfer into industry: examples from the textile machinery secior. IEEE Trans. Eng. Manage., EM-25(1): 15-20.

Rubenstein, A H., 1989. Managing Technology in the Decentralized Firm. John Wiley and Scns, New York: NY.

Schendel, Dan, Patton, G.R. and Riggs, J., 1976. Corporate turnaround strategies: a study of profit decline and recovery, J. Gen. Manage., 3(3): 3-11.

Susman, Gerald I., 1987. The impact of advanced manufacturing technology on the effective utilization of engineers. Working paper 82-3, Collega of Business Adminstration, The Pennsylvania State University.

Wood, Albert R., and Coughlan, Paul D., 1988. Manufacturing engineering profile and manufacturing strategy. Peper presented at the 48th Annual Meeting of the Academy of Management, Anaheim, CA, August 7-10. 